\title{
Almanca ve Türkçede Adın Belirtme Durumu
}

\author{
Prof. Dr. Zeki Uslu \\ Selçuk Üniversitesi Edebiyat Fakültesi \\ Alman Dili ve Edebiyatı Bölümü \\ zekiuslu@selcuk.edu.tr \\ Öz
}

\author{
Dr. Öğr. Üyesi Ayşe Uyanık \\ Selçuk Üniversitesi Edebiyat Fakültesi \\ Alman Dili ve Edebiyatı Bölümü \\ ayseuyanik@selcuk.edu.tr
}

Bu çalışmanın amacı Almanca ve Türkçede adın belirtme durumunu karşılaştırmalı olarak incelemek, benzerlik ve farklılıklarını ortaya çıkarmak ve Almanca öğrenen Türkler için bu konudaki öğrenme zorluklarına çözüm önerileri geliştirmektir. Çalışma iki bölümden oluşmaktadır. Birinci bölümde adın belirtme durumu her iki dilde de ayrıntılı olarak incelenmektedir. Adın belirtme durumunda iki dil arasındaki en belirgin fark nesnenin belirtililik özelliğinde ortaya çıkmıştır. Türkçe tümcede nesne ekli ya da eksiz bulunabilmektedir. -İ ekini alan nesne belirtilidir. Almancada ise nesne ister belirtili ister belirtisiz olsun artikeli mutlaka Akkusativ durumda çekimlenmek zorundadır. İkinci bölümde öğrenci uygulamalarına yer verilmiştir. Öğrencilere çalışma kağıdı dağıtılmış ve üç farklı değişkende adın belirtme durumunu kullanma başarıları ölçülmüştür. Tümce kurmada ve Türkçeden Almancaya çeviride "ein" belirsiz artikelinin Akkusativ durumda çekimlenmemesi, Almancadan Türkçeye çeviride ise belirtisiz nesneye "-i'" ekinin getirilmesi en sık yapılan hatalar olarak bulunmuştur. Hatalar çözümlendiğinde bunların yalnızca Türkçe ile Almancanın yapısal farklılığından kaynaklanmadığı, birinci yabancı dil olarak öğrenilen İngilizcenin de etkisi olduğu anlaşılmıştır. Bu sonuçlara göre öğrencilerin dillere daha çözümleyici yaklaşmasının sağlanması ve dil bilinci oluşturulması yönünde çaba harcanması gerektiği ortaya çıkmıştır.

Anahtar Kelimeler: Ad çekimi, belirtme durumu, nesne, fiil istemi.

\section{The Accusative of the Noun in German and Turkish}

\section{Abstract}

The subject of this study is the accusative of the noun in German and Turkish. The aim of the study is to find similarities and differences in the field of the accusative and to develop solution proposals for learning difficulties. The study consists of two parts. In the first part, the accusative case of the noun is examined in detail in both languages. The biggest difference between two languages is found in the definiteness of the accusative object. The accusative object can be used in Turkish with or without suffix -i. The accusative object with the suffix $-\mathrm{i}$ is determined. But the definiteness of the object must be shown in German with the definite article. The second part examines the students' test. A test has been carried out at Selcuk University, Konya among students in the Department of German Language and Literature. An analysis of the mistakes showed that there are particular problems regarding the translation of Turkish sentences into German and declension of the articles. It became clear that the mistakes not only consist of the structural differences between the two languages, but also that the first foreign language English plays an important role. The foreign language learner must be more careful when comparing languages and their language awareness needs to be developed.

Keywords: Declension of the noun, accusative, object, valence of verbs. 


\section{GİRIS}

Dil edinimi konusunda yapılan araştırmalar insanın anadilinin ya da önceden bildiği dillerin yabancı dil öğrenmede önemli bir etkisi olduğunu göstermektedir (Apeltauer 1997: 88; Klein 1992: 37). Yabancı dil öğrenirken anadili ögelerine sık sık başvurulur. Bu yapı ve ögeler benzerlik taşırsa öğrenme hızlı ve kolay gerçekleşir. Ancak anadili ile yeni öğrenilen dil arasında farklılıklar varsa, öğrenme sürecinin daha dikkatli ve bilinçli oluşturulması gerekir.

Bilindiği gibi Türkçe ve Almanca köken bakımından farklı iki dildir. Türkçe UralAltay dil ailesine ait olup eklemeli bir dil iken, Almanca Hint-Avrupa dil ailesinde yer alan çekimli bir dildir. Doğal olarak farklılıkları benzerliklerinden daha çoktur. Bu nedenle söz varlığı, sözcük yapımı, çekimi, söz dizimi gibi temel dilbilgisi konularının öğrenim ve öğretiminde sorunlarla karşılaşılmaktadır. Bu sorunların aşılmasında gerek kuramsal gerekse uygulamalı çalışmalar özel bir önem taşırlar.

Almanca öğrenen Türklerin en çok yakındı ̆̆ı konulardan birisi artikellerdir. Artikel adın tanımlığı olarak görev yapar. Her ad "der", "die" ve "das" artikelinden birisi ile birlikte kullanılır. Yeni bir sözcük öğrenilirken, artikeli ile birlikte öğrenilmesi gerekir. Çünkü artikeller ilgili sözcügün dilbilgisel cinsi, tekillik çoğulluğu, belirtili belirtisiz olması gibi pek çok özelliğini göstermede işlev üstlenir. Tümce içinde bir adın farklı durumlarda kullanılabilmesi artikelinin değiştirilmesi yoluyla gerçekleştirilir. Almancada bir ad dört farklı durumda çekimlenmektedir. Aşağıdaki örnekte artikellerin önemi görülebilir;

\begin{tabular}{|c|c|c|c|}
\hline Adın durumu & Örnek & $\underline{\text { Belirli Artikel }}$ & $\underline{B e l i r s i z ~ A r t i k e l}$ \\
\hline Yalın durum & Adam & Der Mann & Ein Mann \\
\hline Belirtme durumu & Adam+1 & Den Mann & Einen Mann \\
\hline Yönelme durumu & Adam $+\mathbf{a}$ & Dem Mann & Einem Mann \\
\hline Tamlayan durumu & Adam $+\mathbf{1 n}$ & Des Mannes & Eines Mannes \\
\hline
\end{tabular}

Adlar söz diziminde her zaman yalın durumda kullanılmaz. Tümce içindeki görevine ve yerine göre bu dört durumdan birisinde çekimlenmek zorunda kalırlar. Sözdiziminde bir tümcede kaç tane ad bulunacağı, bu adların hangi durumlarda çekimleneceği fiile bağlı bir konudur. Bağımsal dilbilgisi anlayışına göre fiil tümcenin en önemli ögesidir. Bir tümcede yer alacak ögeleri belirleyen, bağlayan, birleştiren ve yöneten fiildir. Fiilin bu özelliği "fiil istemi" olarak adlandırılır. Fiiller istemleri bakımından farklılık gösterirler. Bazı fiiller tek öge ile yetinirken, bazıları bir, iki ya da üç ögeyi zorunlu tutarlar. Örneğin sehen/görmek, verstehen/anlamak fiilleri tümce içinde belirtme durumunda bir nesne isterken, helfen/yardım etmek, gehören/ait olmak, danken/teşekkür etmek fiilleri yönelme durumunda bir ögeyi gerektirirler. Geben/vermek, zeigen/göstermek fiilleri ise hem yönelme hem de belirtme durumunu birlikte istemektedirler. Birçok dilde fiillerin bu özelliklerini açıklayan istem sözlükleri yazılmıştır. Ancak Türkçede bu konunun henüz yeterince çalışıldığı söylenemez (Doğan 2016). Bu durum hem Türkçenin yabancı dil olarak öğretilmesinde, hem de Almanca öğrenen Türkler için bir sorun olmaktadır (Balcı 2006; Islıoğlu 2014). 
Tümce içinde nesne görevindeki adın kullanım özellikleri dilden dile farklılık gösterir. Türkçenin artikelsiz bir dil olması ve nesnenin belirtililik, belirtisizlik bildirme özelliklerinin Almancadan farklı olması aşağıdaki türden hatalara neden olmaktadır:
a) Roman okuyorum
* Ich lese der Roman
b) Çocuklar pasta yer
* Die Kinder essen der Kuchen
c) Bana kalem ver
* Gib mir Füller!
d) Şirket bir işçi arıyor
* Die Firma sucht ein Arbeiter
e) Öğretmen tahtaya bir cümle yazıyor
* Der Lehrer schreibt ein Satz an die Tafel

$\mathrm{Bu}$ örneklere bakıldığında hataların Türkçedeki yapıların bire bir aktarılmasından kaynaklandığı görülüyor. Bütün örneklerdeki nesneler yüzeysel olarak yalın durumda görüldüğü için Almancaya hatalı biçimde yalın durumda aktarılmıştır. (a), (b) ve (c) örneklerinde nesneler belirtili olsaydı, Türk öğrenci Almancasında artikellerini Akkusativ yapabilirdi. Ancak nesnenin belirtili olması Türkçede tümceye çok farklı anlam özellikleri katardı, yani anlam değeri değişirdi. (d) ve (e) örneklerinde Türkçede nesnenin önüne "bir" getirilerek belirtisiz olduğu vurgulanmaktadır. Türkçede belirtisiz nesneye -İ eki getirilmez. $\mathrm{Bu}$ önbilgiye dayanarak ilgili örneklerin de Almancaya hatalı aktarıldığını görüyoruz. Burada iki dilin farklı özelliklerinin dikkate alınmadığı anlaşılıyor. En temel fark fiil isteminde ortaya çıkmaktadır. Türkçe örneklerde bulunan nesneler yalın durumdadır. Türkçede -İ belirtme ekini almayan bir nesnenin belirtisiz nesne olduğu bilinir. Çünkü -i் belirtme eki nesneye özel bir anlam yüklemektedir. Buradaki yüklemler nesneyi hem yalın durumda yani belirtisiz, hem de belirtme durumunda kabul edebilmektedir. Nesne durumunun belirlenmesinde fiil istemi dışında sözdizimsel ve anlamsal faktörler de rol oynar. Oysa Almanca örneklerde geçen fiiller tümcedeki nesneyi mutlaka belirtme durumunda istiyorlar. Nesne ister belirtili ister belirtisiz olsun mutlaka Akkusativ (-İ durumu) çekimli olarak kullanılması gerekmektedir. Almancada bu kesin bir dilbilgisi kuralıdır.

Görüldüğü gibi adın belirtme durumu Almanca öğrenen Türkler için oldukça karmaşık bir konudur. Öğrencilerin Almancada adın durumlarını doğru kullanım düzeyini araştıran Çelik ve Sakarya Maden (2016) başarı oranının çok düşük olduğunu saptamışlardır. Adın belirtme durumu ile ilgili öğrenme zorluğu özellikle dilbilgisi ve çeviri derslerinde yaşanmaktadır. Bu çalışmanın çıkış noktası Almanca Bölümü öğrencilerinin adı geçen konuda yaşadıkları öğrenme zorluklarına dayanmaktadır. Çalışmanın amacı Almanca ve Türkçe dil çiftinde adın belirtme durumunu karşılaştırmalı olarak incelemek, Almanca derslerinde yaşanan öğrenme zorluklarını uygulamalı olarak belirlemek ve daha başarılı bir öğrenme süreci için öneriler geliştirmektir.

\section{ALMANCADA ADIN BELIRTME DURUMU}

Almancada bir adın farklı durumlara dönüştürülmesi artikelinin çekimlenmesiyle gerçekleştirilir. Bir adın dört faklı durumda çekimlenmesi mümkündür (Duden 1995: 217); yalın durum (Nominativ), belirtme durumu (Akkusativ), yönelme durumu (Dativ) ve tamlayan durumu (Genitiv). Konumuz olan belirtme durumu "kimi?" "neyi?" sorularına yanıt verir ve aşağıdaki gibi çekimlenir; 
Tekil

\begin{tabular}{|c|c|c|c|}
\hline Yalın durum & der Vater & die Mutter & das Kind \\
\hline Belirtme durumu & den Vater & die Mutter & das Kind \\
\hline \multicolumn{4}{|l|}{ Çoğul } \\
\hline Yalın durum & die Väter & die Mütter & die Kinde \\
\hline \multirow[t]{2}{*}{ Belirtme durumu } & die Väter & die Mütter & die Kinde \\
\hline & \multicolumn{2}{|c|}{ Belirsiz Artikel Çekimleri } & \\
\hline \multicolumn{4}{|l|}{ Tekil } \\
\hline Yalın durum & ein Vater & eine Mutter & ein Kind \\
\hline Belirtme durumu & einen Vater & eine Mutter & ein Kind \\
\hline \multicolumn{4}{|l|}{ Çoğul } \\
\hline Yalın durum & Väter & Mütter & Kinder \\
\hline Belirtme durumu & Väter & Mütter & Kinder \\
\hline
\end{tabular}

Tabloda görüldüğü gibi Almanca adlar belirtme durumunda çekimlenirken yalnızca "der" artikelinde değişim yapılıyor. "Der Vater" (baba) "den Vater" (babayı) olarak çekimlenirken, aynı kural belirsiz artikel çekimlerinde de uygulanıyor. Yalın durumdaki "ein Vater" belirsiz adı, "einen Vater" biçimine dönüştürülüyor. Buradaki çekim yalnızca belirli "der" artikelindeki değişimin belirsiz "ein" artikeline de uygulanmasıdır. Yoksa Akkusativ çekimi yapılan belirsiz adı belirli duruma getirmemektedir. Yani "einen Vater" belirtili nesne değildir. Vater adının önündeki "ein" onu belirsiz yapmaktadır. Belirsiz artikelde yapılan bir çekim adın belirsizlik özelliğini etkilemez. İşte bu durum, Akkusativ'in belirtme durumu ya da -İ hali olarak adlandırılmasında bir sorun olarak değerlendirilebilir. Çünkü Türkçede adın sonuna eklenen -İ takısı onu belirtili nesne yapar. Belirtisiz nesnelerde -İ takısı kullanılmaz. Almanca ve Türkçe arasındaki bu fark dilbilgisi ve çeviri derslerinde bir öğrenme zorluğu olarak ortaya çıkmaktadır.

Almanca sözdiziminde bir adın hangi durumda kullanılacağını belirleyen iki temel öge bulunmaktadır; fiil ve ilgeç. Tümcenin yüklemi olan fiil, tümce içindeki adları yönetir. Nesne görevindeki adların durumunu belirler. Bu durum fiil istemi olarak adlandırılır. Almancada fiillerin büyük çoğunluğu tümce içinde adın belirtme durumunda olmasını ister (Dreyer-Schmidt 2006: 70). Sehen, kennen, lieben, fragen, kaufen, suchen, rufen, lesen, besuchen, haben, verlassen, verstehen gibi.

Der Fahrer verlässt den Bus. / Sürücü otobüsü terk ediyor.

Die Polizei sucht den Mann. / Polis adamı arıyor.

Der Lehrer ruft den Schüler. / Öğretmen öğrenciyi çağırıyor.

Adın durumunu belirleyen ikinci temel faktör ise ilgeçlerdir (Präposition). Almancada bazı ilgeçler yalnızca belirtme durumu isterler. Bunlara örnek olarak für, durch, ohne, gegen, entlang, um sayılabilir. Diğer bazı ilgeçler ise hem belirtme hem de yönelme durumunda kullanılabilir; an, auf, in, unter vb. Böylece tümce içinde yüklemle ve diğer adlarla çeşitli anlam ilişkileri kurarlar. 
Sie arbeitet für ihren Sohn. / Oğlu için çalışıyor.

Er legt das Buch auf den Tisch. / Kitabı masanın üstüne koyuyor.

Almancada bazı fiiller bir ilgeçle kalıp oluştururlar. Tümcede nesnenin önüne belirli bir ilgecin gelmesini isterler. Bu tür fiiller ile tümce kuruluyorsa gereken ilgeç mutlaka kullanılmalıdır. Kullanılan ilgeç de nesneyi istediği duruma dönüştürür. Örnek;

denken an $(\mathrm{A})$

warten auf (A)

sich interessieren für $(\mathrm{A})$ birini, bir şeyi düşünmek

birini, bir şeyi beklemek

biriyle, bir şeyle ilgilenmek

Ich denke an meine Mutter. / Annemi düşünüyorum.

Der Student wartet auf den Bus. / Öğrenci otobüs bekliyor.

Bu yapılarda ilgeçlerin tek başlarına bir anlam taşımadığı, yüklemin bir parçası olarak görev yaparak tümce içindeki nesneyi etkilediği görülüyor. Türkçe tümcelerde bu ilgeçlerin etkilediği nesne ekli ya da eksiz olarak bulunabiliyor. Ayrıca anlam ve durum eşdeğerliği olmayabiliyor. Almanca ve Türkçede fiillerin istem özeliklerinin karşılaştırıldığı uygulamalı bir çalışmada farklılık oranı yüzde elli altı olarak bulunmuştur (Balcı 2009: 58).

\section{TÜRKÇEDE ADIN BELİRTME DURUMU}

Türkçede adlara sözdiziminde üstlendiği göreve göre belli ekler getirilir. Adın durumunu gösteren bu ekler çekim ekleridir. Dilbilgisinde ad çekimi ya da adın durumu olarak işlenen bu konuda henüz bir kavram birliği sağlanamamıştır. Batı dillerindeki Akkusativ kavramının karşılığı olarak Türkçe dilbilgisi kitaplarında $-\dot{I}$ durumu Gencan (1979: 155), kimi hali Banguoğlu (1998: 326), yükleme durumu Korkmaz (2003: 266) ve belirtme durumu Hengirmen (1998: 123) kavramları kullanılmaktadır. Türkçe sözdiziminde tartışmalı konulardan biri de nesnedir. Nesne tanımlanırken genelde şu özellikleri üzerinde durulmaktadır; fiilin etkilediği varlığı karşılama, öznenin ve yüklemim yaptığı işi belirtme ve geçişli fiili tümleme. Nesne Akkusativ ekli ya da eksiz bulunabilir (Banguoğlu 1998; Ergin 1993). Geçişli fiillerin istemine göre tümcede yar alan bu sözcükler "belirtili nesne" ,"belirtisiz nesne","düz tümleç" olarak adlandırılmaktadır. Ancak Akkusativ dışında diğer ad durum eklerini alan kelimeler de nesne olarak kabul edilmekte ve bunlar "dolaylı tümleç" kavramıyla karşılanmaktadır (Balcı 2013; Kaçar 2016). Karahan (1999) nesne durumunu adın diğer durumlarından ayırır. Ona göre belirtme durumu eki yükleme hâli ekidir ve fonksiyonu eklendiği kelimeyle sınırlıdır.

Nesne görevindeki adlar belirtili ya da belirtisiz olabilir. Bir ad belirtili nesne olarak kullanılırsa "kimi?", "neyi?" sorularına yanıt verir ve adın sonuna -i̇ eki eklenir. Nesne yalın durumdaysa belirtisizdir ve ek almaz. Nesnenin belirtili olup olmaması, tümcede yer alan ögelerin sözdizimsel ve anlamsal ilişkilerine de bağlıdır (Johanson 1977: 227). Örneğin; “biz, içmek, çay, balkon" ögeleriyle kurulabilecek tümceleri inceleyelim. 

a) Balkonda çay içtik.
b) Çay içtik balkonda.
c) İçtik çayı balkonda.
d) Çayı balkonda içtik.

"İçmek" fiili zorunlu olarak bir nesne istemektedir. "biz içtik" biçimindeki bir tümce anlamca eksik olurdu. "biz çay içtik" tümcesi anlamlı ve yeterli olmaktadır. Ancak tümceye zorunlu olmayan, seçimlik ögeler de eklenebilir. Bu örnekte "balkonda" ögesi ile bulunma durumunda çekimlenmiş bir ad yer almış ve tümceyi anlamca biraz daha genişletmiştir. Burada (a) ve (b) örneklerinde nesne belirtisiz olarak "çay" biçiminde yer almaktadır. (c) ve (d) örneklerinde nesnenin belirtili olma zorunluluğu ortaya çıkmıştır. Nesnenin sözdizimindeki yerlerine baktığımızda belirtisiz olanların yüklemin hemen önünde, belirtili olanları ise ya ilk sırada ya da yüklemden sonra yer aldığını görüyoruz. Demek ki sözdiziminde nesnenin bulunduğu yer, belirtili ya da belirtisiz olmasında önemli bir rol oynamaktadir.
e) Bugün bir ödev yaptım.
f) Bugün ödev yaptım.
g) *Bugün ödevim yaptım.
h) *Dünkü ödev yaptın $\mathrm{m}$ ?
1) *Bu ödev yaptın $\mathrm{mi}$ ?

Yüklemin önünde yer alan nesneye eğer farklı biçimbirimler ya da niteleyicilerle özel anlamlar yüklenmişse bu tür nesneler mutlaka belirtili olmak zorundadır. (e) örneğinde nesnenin önüne "bir" getirilerek yapılan ödevin belirsiz olduğu, "herhangi bir" ödev olduğu açıkça yazılmıştır. (f) örneğinde belirsizlik eki "bir" yoktur. Fakat nesne başka bir yolla belirtilmediği için yine "herhangi bir" anlamı taşımaktadır ve belirsizdir. "Bir" sözcüğü kullanılmadan nesnenin nasıl belirtisiz anlam taşıdığı incelenmesi gereken bir konudur. Oysa (g), (h) ve (1) örneklerinde nesneye anlamlar yüklendiği ve böylece belirtildiği için -İ eki olmadan kullanılamamaktadır. Bu örneklerde iyelik eki, gösterme sıfatı ve -Ki ekinin nesneleri belirtili yapmada görev aldıklarını görüyoruz. Türkçenin anadili konuşucuları için nesnenin neye göre belirtili ya da belirtisiz olarak kullanılacağını bilmek ya da hissetmek çok kolay olabilir. Ancak yabancı dil olarak öğrenenler için pek de öyle olmadığı görülmektedir. Bu nedenle kuralların net olarak belirlenmesi ve dilbilgisi kitaplarında yer almasi gerekir.

\section{4. ÖĞRENCİ UYGULAMALARINDA ADIN BELİRTME DURUMU}

Bu bölümde Almanca öğrencilerinin adın belirtme durumunu kullanmada yaptıkları hata türleri ve bunların sıklık düzeyi belirlenmeye çalışılacaktır. Bu amaçla Selçuk Üniversitesi Edebiyat Fakültesi Alman Dili ve Edebiyatı Bölümünde 170 öğrenciyle bir uygulama yapılmıştır. Öğrencilere üç bölümden oluşan bir çalışma kağıdı dağıtılmış ve soruları cevaplandırmaları istenmiştir. Her bölümde beş tümce verilmiştir. Tümceler özne, nesne ve yüklemden oluşan kolay yapıdadır. Nesne görevindeki sözcüklerin 
belirlenmesinde belirli artikel, belirsiz artikel ve iyelik adıllı tamlama gibi farklı biçimbilgisel özelliklerin bulunmasına özen gösterilmiştir. Böylece Almanca öğrencilerinin ne tür yapılarda sıklıkla hata yaptıklarının belirlenmesi amaçlanmıştır.

Çalışma kağıdının birinci bölümünde Almanca sözcükler verilerek tümce kurmaları istenmiştir. Burada adlar artikelleriyle birlikte yalın durumda ve fiiller mastar biçiminde verilmiştir. Verilen sözcükler A1 düzeyinde herkesin anlayabileceği temel sözcüklerdir. İkinci bölümde Türkçe tümceler verilerek Almancaya çevirmeleri istenmiştir. Amaç öğrencilerin sözcük dağarcığını ölçmek olmadığı için Türkçe tümcede geçen her sözcüğün Almancası ayraç içinde yazılmıştır. Üçüncü bölümde Almanca tümceler verilerek Türkçeye çevirmeleri istenmiştir. Türkçeden çeviri yaparken, Almanca hazır verilen tümcelerden örnekseme yoluyla yararlanma olasılıkları öngörülerek bu bölüm çalışma kağıdının son kısmına ve kağıdın arka yüzüne yazılmıştır. Uygulama sınıf ortamında ve gözetmen eşliğinde gerçekleştirilmiştir.

\subsection{Verilerin Çözümlenmesi}

Uygulamadan elde edilen veriler SPSS programıla istatistiksel olarak çözümlenmiştir. Çözümlemede yalnızca tümcenin nesnesi konu edilmiş, sözdiziminde yer alan diğer ögeler değerlendirme dışı bırakılmıştır. En çok kullanılan yapılar yüzdeleriyle birlikte gösterilmektedir. Yüzdesi çok düşük olan seyrek kullanımlara yalnızca yorumlarda yer verilmektedir. Adın belirtme durumu konusunda öğrencilerin başarı düzeyleri, yapılan hataların türleri ve olası nedenleri üç farklı değişkende ele alınmıştır.

\subsubsection{Tümce Kurmada}

1- Der Schüler / der Satz / schreiben.

a) Der Schüler schreibt den Satz. (\% 73.5)

b) Der Schüler schreibt der Satz. (\% 21.8)

2- Der Mann / der Ausländer / verstehen / nicht.

a) Der Mann versteht den Ausländer nicht. (\% 57.1)

b) Der Mann versteht der Ausländer nicht. (\% 36.9)

3- Ich / ein Roman / lesen.

a) Ich lese einen Roman. (\% 27.1)

b) Ich lese ein Roman. (\% 69.5)

4- Das Kind / sein Onkel / besuchen.

a) Das Kind besucht seinen Onkel. (\% 47.6)

b) Das Kind besucht sein Onkel. (\% 42.4)

c) Das Kind besucht seinem Onkel. (\% 10)

5- Wir / der Bus / warten auf.

a) Wir warten auf den Bus. (\% 78.8)

b) Wir warten auf der Bus. (\% 20.5)

Yukarıdaki tümcelerde yer alan fiillerin tamamı tümce içindeki nesneyi belirtme durumunda istemektedir. Bu temel bir kuraldır. Öğrencilerin verileri incelendiğinde bu kuralın uygulanmadığı görülmektedir. Başarı oranının en yüksek olduğu örnek $5 a^{\prime}$ dır. Bu örnekte "auf" ilgeci bulunduğundan, öğrenciler ilgeçten sonra gelen artikelin çekimli olması gerektiğini düşünmüş olabilirler. En çok hatanın $3 b^{\prime}$ de olduğunu görüyoruz. Burada anadillerinin etkisi ortaya çıkmıştır. Çünkü Türkçede belirtisiz nesnenin önünde "bir" 
olunca nesne çekim eki almamaktadır. Ayrıca "okumak" fiili tümce içindeki nesneyi ekli ya da eksiz alabilmektedir. Bu tür tümcelerde nesnenin sözdizimindeki yeri, belirtili olup olmamasında, yani ek alıp almamasında önemli rol oynamaktadır. Almanca ve Türkçe arasındaki farklılık bu tümcedeki hataların önemli bir kaynağı olarak görülebilir. "Verstehen/anlamak" ve "besuchen/ziyaret etmek" fiillerinin istemi iki dilde de örtüşmektedir. "Yabancı anlamak" ya da "amca ziyaret etmek" gibi kullanımlar hemen kulak tırmalamaktadır. Bu fiillerle kurulan bir tümcede nesnenin çekimsiz/eksiz kullanılması olanaksızdır. Buna rağmen hata oranı yüzde kırk civarında bulunmuştur. Bu yüksek bir orandır. 4c örneğinde nesne işlevindeki ad yönelme durumunda çekimlenmiştir. Burada öğrencinin gereksiz yorum yaparak "ziyaret etmek" fiili yerine yönelme durumu isteyen "uğramak" fiilini düşündüğü değerlendirilebilir.

Hatalar çözümlendiğinde, bunların tek bir nedene bağlanması olanaksız görülmektedir. Anadili ile öğrenilen yabancı dilin farklılı̆̆ı tek neden olarak ortaya çımamaktadır. Eğer öyle olsaydı fiil isteminin benzediği tümceleri doğru yapmaları beklenirdi. Belki burada öğrendikleri birinci yabancı dilin etkisinden söz edilebilir. Çünkü İngilizce sözdiziminde nesne herhangi bir çekim yapılmadan kullanılmaktadır. Yabancı dil öğrencilerinde dil bilinci oluşturulması ve öğrencilerin dile daha çözümleyici bir anlayışla yaklaşmaları sağlanmalıdır.

\subsubsection{Türkçeden Almancaya Çeviride}

1- Doktor hastayı muayene ediyor. (Der Arzt / untersuchen / der Kranke)

a) Der Arzt untersucht den Kranken. (\% 70.6)

b) Der Arzt untersucht der Kranke. (\% 25.3)

c) Der Arzt untersucht dem Kranke. (\% 4.7)

2- Öğrenci bir roman okuyor. (Der Schüler / lesen / ein Roman)

a) Der Schüler liest einen Roman. (\% 25.9)

b) Der Schüler liest ein Roman. (\% 71.8)

3- Çayı balkonda içiyoruz. (Wir / trinken / der Tee / auf dem Balkon)

a) Wir trinken den Tee auf dem Balkon. (\% 64.7)

b) Wir trinken der Tee auf dem Balkon. (\% 33.5)

4- Şoför adamı görmüyor. (Der Fahrer / der Mann / sehen / nicht)

a) Der Fahrer sieht den Mann nicht. (\% 76.5)

b) Der Fahrer sieht der Mann nicht. (\% 19.4)

5- Okul iyi bir öğretmen arıyor. (Die Schule / ein guter Lehrer / suchen)

a) Die Schule sucht einen guten Lehrer. (\% 12.9)

b) Die Schule sucht ein guter Lehrer. (\% 84.7)

Türkçe bir tümceyi yabancı dile aktarma, genelde öğrencilerin en çok zorlandıkları çalışmalardır. Bunun nedeni amaç dildeki eksiklikleri olarak açıklanabilir. Burada dillerin benzerliği yardımcı bir işlev üstlenmektedir. 1a, 3a ve 4a örneklerinde başarı oranının yüksek olduğunu görüyoruz. Çalışmaya katılanların yüzde yetmişten fazlası tümcelerin nesnesi olan adı doğru durumda çekimlemiştir. Çünkü Türkçesinde de nesne belirtilidir. "Hastayı", "çayı" ve "adamı" biçimindeki belirtme durumu ekli adlar Almancaya aktarılırken yalın durumda verilmemiştir. Oysa "bir roman" ve "iyi bir öğretmen" biçimindeki nesneler eksiz olarak yalın durumda görüldüğü için öğrenci bunları yanlış çevirmektedir. Bu örneklerde başarı oranı çok düşmektedir. Katılımcılar tümcenin 
sözdizimsel ve anlamsal özelliğini değil de yüzeysel yapısını dikkate alarak bire bir çeviri yapmaktadirlar $(2 a, 5 a)$.

Nesnenin belirtilmesi konusu Almanca ile Türkçenin farklılıklarından biridir. Türkçede nesnenin ekli ya da eksiz bulunabilmesi, Almancada ister belirtili isterse belirsiz belirtisiz olsun artikelin mutlaka Akkusativ durumda çekimlenmesi öğrencilerin bilmesi gereken temel bir kuraldır. Bu konunun yabancı dil öğrencilerine özümsetilmesi bir zorunluluk olarak ortaya çıkmaktadır.

\subsubsection{Almancadan Türkçeye Çeviride}

1- Verstehst du diesen Satz?

a) Bu cümleyi anliyor musun? (\% 100)

2- Die Katze frisst eine Maus.

a) Kedi bir fare yiyor. (\% 50)

b) Kedi bir fareyi yiyor. (\% 50)

3- Der Schüler liest einen Text.

a) Öğrenci bir metin okuyor. (\% 55.9)

b) Öğrenci bir metni okuyor. (\% 44.1)

4- Meinen Onkel werde ich morgen besuchen.

a) Amcamı yarın ziyaret edeceğim. (\% 75.9)

b) Amcam yarın beni ziyaret edecek. (\% 24.1)

5- Der Mann kauft sich einen neuen Bus.

a) Adam kendine yeni bir otobüs alıyor. (\% 100)

Yabancı dilden anadiline yapılan çeviriler göreceli olarak daha başarılıdır. Çünkü anadilimiz en güçlü olduğumuz dildir. Sözcük dağarcığında, sözdizimsel yapıda ve diğer kullanım özelliklerini tanımada yeterli olmamız beklenir. Bu nedenle yabancı dilden bir tümceyi anadilimize aktarırken farklı seçeneklerimiz vardır ve bunlar arasından en uygununu bulmaya çalışırız. Beklendiği gibi bu bölümde öğrencilerin başarıları daha yüksektir. Özellikle 1a ve 5a örneklerinde yüksek başarı görülmektedir. 1. Örnekte nesnenin Akkusativ çekimli olması ve "anlamak" fiilinin" Türkçede de "belirtili nesne" istemesi benzerliklerin başarıyı artırmasında önemli rol oynadığını göstermektedir. 5. Örnekte ise Almanca tümcede nesne Akkusativ çekimli olmasına rağmen öğrenciler doğru çözümleme yaparak Türkçede belirtisiz nesnenin özelliğine uygun çeviri yapmışlardır. Ancak bu çözümlemenin 2 ve 3 numaralı örneklerde yapılmadığı görülmektedir. Türkçede belirtisiz nesnenin ek almayacağ kuralını bilen bir anadili konuşucusundan "kedi bir fareyi yiyor" ya da "öğrenci bir metni okuyor" biçimindeki yanlış kullanımlar beklenmezdi. Aynı kuralın farklı örneklerde farklı uygulanması, öğrencilerin bu konuda eksikliğini gösterir. Dilbilgisi alanındaki yetersizlikler öğrencilerde güven eksikliğine yol açmakta ve onları hataya sürüklemektedir. 


\section{SONUÇ}

Almanca ve Türkçede adın belirtme durumunun karşılaştırıldığı ve öğrenci uygulamalarının incelendiği bu çalışmada aşağıdaki sonuçlara ulaşılmıştır;

a) Almancada artikel dönüşümü ile gerçekleştirilen ad durumları Türkçede sonekler yardımıyla sağlanmaktadır. Adın belirtme durumu konusunu bu iki dil farklı yorumlamaktadır. Almancada nesne görevindeki sözcük ister belirtili olsun, ister belirtisiz olsun artikeli mutlaka çekimlenmek zorundadır. Türkçede ise nesne belirtme durumu ekli ya da eksiz kullanılabilmektedir.

b) Almanca ve Türkçede fiillerin istemi yüzde elli civarında örtüşmektedir. Türkçede yönelme durumu gerektiren bir fiil Almancada belirtme durumu isteyebilmektedir. Almancada bazı fiiller nesnenin önünde belirli ilgeçleri istemektedir. Bu özellik Türkçe fiillerde bulunmaz. Fiiller öğrenilirken istemi ile birlikte öğrenilmelidir.

c) Sözdizimi, Türkçede adın belirtme durumu ekini alıp almamasında belirleyici bir rol oynamaktadır. Yüklemin önünde yer alan ad yalın durumda olursa, belirtisiz nesne görevindedir, -İ eki almışsa belirtili nesnedir. Ancak tümce içinde nesne görevindeki ad yer değiştirirse, yani yüklemin önünde bulunmazsa mutlaka -İ eki alır ve belirtili durumda kullanılır. Almancada nesnenin sözdizimindeki yeri adın durumunu belirlemede rol oynamaz.

d) Öğrenci uygulamalarında hatalar adın belirtme durumunun kullanıldığı yere göre değişmektedir. Tümce kurmada ve Türkçeden Almancaya çeviride "ein" belirsiz artikelinin belirtme durumunda çekimlenmemesi, Almancadan Türkçeye çeviride ise belirtisiz nesneye "-İ" ekinin getirilmesi en sık yapılan hatalar olarak bulunmuştur. Hatalar çözümlendiğinde bunların yalnızca Türkçe ile Almancanın yapısal farklılığından kaynaklanmadığı görülmektedir. Çünkü fiil istemi gibi benzeyen özelliklerde de hatalar saptanmıştır. Adın belirtme durumunu kullanmada ortaya çıkan hataların hem anadili Türkçe hem de birinci yabancı dil olarak öğrenilen İngilizcenin etkisiyle yapıldığı değerlendirilmektedir.

$\mathrm{Bu}$ sonuçlara göre, Türkçe - Almanca dil çiftinin adın belirtme durumunu yorumlamada farklılıkları olduğu, Almanca öğrencilerinin hem anadilleri Türkçeden hem de birinci yabancı dilleri İngilizceden etkilendiği, dil bölümü öğrencilerinin dillere daha çözümleyici yaklaşmasının sağlanması ve dil bilinci oluşturulması yönünde çaba harcanması gerektiği ortaya çıkmıştır.

\section{SUMMARY}

The research on language acquisition shows that the native language and the previously learned languages exert an influence on the appropriation of a foreign language. While learning foreign languages, we orient ourselves towards structures and elements of our first language. When structures and elements are similar, you learn easier and faster. Differences between languages cause learning difficulties. So the learning process has to be deliberately planned.

As you know, German and Turkish are two different languages. Turkish belongs to Ural-Altay languages and is an agglutinative language. German, on the other hand, belongs to Indo-European languages and is an inflecting language. Differences are more than similarities. An important difference is that Turkish has no articles. For this reason, the declension of the noun is very different. Thus, the case of nouns arises as a learning problem. 
This study is based on the observation that Turkish learners of German have learning difficulties in the case of nouns. When using the accusative they make many mistakes. The aim of the study is to find similarities and differences in the field of the accusative and to develop proposals to solve the learning difficulties. The study consists of two parts. In the first part, the accusative of the noun is examined in detail in both languages. The biggest difference between two languages is found in the definiteness of the accusative object. The accusative object can be used in Turkish with or without suffix -I. The accusative object with the suffix -I is determined. But the definiteness of the object must be shown in German with the definite article.

The second part examines the students' test. A test has been carried out at Selcuk University, Konya among students of German Language and Literature Department. The definiteness of the object in the sentence differs in the German-Turkish language pair. In Turkish, the object can be used either in the nominative or in the accusative. When the object is determined, it is used in the accusative with suffix -i. If the object is not determined, it is used in the nominative. In contrast, in German, the object must necessarily be declined. It does not matter if it is determined or not. The syntax plays a significant role in Turkish for the definiteness of the object. If the object is in front of the predicate, it can be in the nominative and acts as an indefinite object. In the case that it is supplemented with the suffix $-\mathrm{I}$, it is a definite object. But, if there is a conversion of the object, then it must be used with the suffix -I. The valence of the verbs is approximately fifty percent congruent. Some verbs are used in German with a specific preposition. These prepositions have no equivalents in Turkish. They have to be used together with the verbs.

The study has revealed that native speakers of Turkish make many mistakes when using the accusative. An analysis of the mistakes showed that there are particular problems regarding the translation of Turkish sentences into German and declension of the articles. Most mistakes occur in sentence formation and translations from Turkish to German. The students use the indefinite article "ein" not declined in the accusative. When translating from German to Turkish, they add the suffix "-I" to the indefinite object. The analysis of the mistakes revealed that the errors are not only dependent on the structural difference between the two languages, but also in the area of similarities like "such as". Errors were detected in the valence of verbs. So it can be said that the mistakes made in using the accusative were due to the influence of both of languages, Turkish and the first foreign language English.

From these findings, it can be concluded that the accusative in German as a second foreign language should be better communicated in the future, especially in textbooks for Turks. The foreign language learner must be more careful when comparing languages and their language awareness needs to be developed. 


\section{KAYNAKÇA}

Apeltauer, Ernst (1997). Grundlagen des Erst- und Fremdsprachenerwerbs. Berlin: Langenscheidt.

Balc1, Tahir (2006). Valenzstrukturabhängige Probleme beim DaF-Lernen türkischer Studierender. DaF, 4 Quartal. Herder Institut. Leibzig. 239-241

Balc1, Tahir (2009): Grundzüge der Türkisch-Deutschen Kontrastiven Grammatik. Adana: Ulusoy Matbaası.

Balc1, Umut (2013). Direkte und indirekte Objekte im Deutschen und Türkischen. Turkish Studies - International Periodical For The Languages, Literature and History of Turkish or Turkic 8/1. 871-879

Banguoğlu, Tahsin (1998). Türkçenin Grameri. Ankara: TDK Yay. 5. bs.

Çelik, Aylin Jale-Sakarya Maden, Sevinç (2016). Eine Studie zur Ermittlung der Einstellung der Lehramtskandidaten für Deutsch bezüglich der Kasusdifferenzierung im Deutschen. Trakya Üniversitesi Sosyal Bilimler Dergisi 18/1. 159-176.

Doğan, Nuh (2016). İstem Sözlükleri ve Türkçe. The Journal of Academic Social Science Studies $42,251-268$

Dreyer, Hilke-Schmidt, Richard (2006). Lehr-und Übungsbuch der deutschen Grammatik. München: Hueber.

Duden (1995). Duden 4. Grammatik der deutschen Gegenwartssprache. Mannheim: Dudenverlag. Ergin, Muharrem (1993). Türk Dil Bilgisi. İstanbul: Bayrak Yay.

Gencan, Tahir Nejat (1979). Dilbilgisi. Ankara: TDK Yay.

Helbig, Gerhard-Buscha, Joachim (1988). Deutsche Grammatik. Ein Handbuch für den Ausländerunterricht. Leibzig: Veb Verlag Enzyklopädie.

Hengirmen, Mehmet (1998). Türkçe Dilbilgisi. Ankara: Engin Yay.

Islıŏlu, Selma (2014). Yabancı Dil olarak Türkçenin Öğretiminde Nesne Durum Ekinin Kullanımı ile ilgili Yanlışlar ve Çözüm Önerileri. Route Educational and Social Science Journal 1 (2). 101-115

Johanson, Lars (1977). Bestimmtheit und Mitteilungsperspektive im türkischen Satz. Zeitschrift der Deutschen Morgenländischen Gesellschaft. 1186-1203

Kaçar, Erdal (2016). Eylem-Eyleyen İlişkisi Bağlamında Nesne Kavramı. Diyalog interkulturelle Zeitschrift für Germanistik 1. 29-39

Karahan, Leyla (1999). Yükleme (accusative) ve İlgi (genitive) Hâli Ekleri Üzerine Bazı Düşünceler. 3. Uluslararası Türk Dil Kurultayı 1996. Ankara: Kılıçaslan Matbaacılık. 605611

Klein, Wolfgang (1992). Zweitspracherwerb. Studienbuch Linguistik. Frankfurt: Anton Hain

Korkmaz, Zeynep (2003). Türkiye Türkçesi Grameri. Ankara: TDK Yay.

Uslu, Zeki (2016). Türkçe-Almanca Karşılaştırmalı Temel Dilbilgisi. Ankara: Anı Yay. 